\title{
Immunohistochemical clue for the histological overlap of salivary adenoid cystic carcinoma and polymorphous low-grade adenocarcinoma
}

\author{
SHERIF Y. EL-NAGDY, NAGLAA M. SALAMA*, MOHAMED I. MOURAD \\ Oral Pathology Department, Faculty of Dentistry, Mansoura University, Mansoura, Egypt \\ *Corresponding author: Naglaa M. Salama, assistant professor of oral pathology; Oral Pathology Department, Faculty of Dentistry, \\ Mansoura University, Mansoura, Egypt; E-mail: naglasalama@ymail.com
}

(Received: June 10, 2013; Revised manuscript received: July 20, 2013; Accepted: July 22, 2013)

\begin{abstract}
It remains difficult to distinguish adenoid cystic carcinoma (ACC) from polymorphous low-grade adenocarcinoma (PLGA). Although these neoplasms exhibit nearly similar histologic patterns, their biologic behavior is significantly different. This study was carried out in an attempt to overcome the histological overlap between these tumors using immunohistochemical method for c-kit and galectin-3 proteins on twenty cases of salivary gland tumors including twelve ACC and eight PLGA. Results revealed positive cytoplasmic reactivity for c-kit in $100 \%$ of ACC cases and only in 25\% of PLGA. On the other hand, galectin-3 expression was observed in 100\% of both ACC and PLGA cases. Moreover, solid variant of ACC showed overexpression of both proteins than cribriform and tubular subtypes. Significant positive correlation between the two studied proteins in ACC and PLGA was also observed $(p<0.05)$. Upon these results, over expression of c-kit and galectin-3 in ACC cases supports the concept of solid variant as a high-grade tumor. Moreover, c-kit may be used as a helpful marker to distinguish ACC from PLGA in cases where the diagnosis can be challenging.
\end{abstract}

Keywords: c-kit, galectin-3, adenoid cystic carcinoma (ACC), polymorphous low-grade adenocarcinoma (PLGA)

\section{Introduction}

Salivary gland tumors (SGTs) constitute an important area in the field of oral and maxillofacial pathology. Their incidence around the world ranges from about 1.0 to 6.0 cases per 100,000 people per year, and they represent $2-4 \%$ of head and neck neoplasms [1]. Adenoid cystic carcinoma (ACC) and polymorphous low-grade adenocarcinoma (PLGA) are malignant salivary gland tumors that represent diverse clinical behavior [2].

ACC is the third most common malignant salivary gland tumor overall (after mucoepidermoid carcinoma and PLGA). It represents $28 \%$ of malignant submandibular gland tumors, making it the single most common malignant salivary gland tumor in this region [3]. ACC occurring in the minor salivary glands of the head and neck tends to spread along nerves [4]. ACC is a malignant tumor with a deceptively benign histologic appearance. Numerous studies have attempted to elu- cidate accurate histologic prognostic features but have often yielded conflicting results [5-7].

PLGA is the second most common type of malignant neoplasm in minor salivary glands, primarily those in the palate. Its origin in major salivary glands is considered exceedingly rare [8]. PLGA was first reported in 1983 by two different groups under the terms lobular carcinoma of the salivary glands and terminal duct carcinoma and since that it has become an established clinicopathologic entity $[9,10]$. It has unique clinical, histomorphologic and behavioral aspects [11]. Owing to its location and its distinct cribriform pattern, this lesion was initially diagnosed as an unusual variant of ACC [12].

Both ACC and PLGA are believed to originate from the intercalated duct, as both are composed of both luminal epithelial and abluminal myoepithelial cells [13]. The overlapping clinicopathological features of PLGA and ACC may result in a diagnostic pitfall. ACC has a 
much worse prognosis than PLGA, making differentiation important for therapeutic and prognostic purposes [14-16]. The biologic behavior of ACC and PLGA is significantly different. ACC is characterized by slow relentless growth, with late recurrences, extensive bony and soft tissue invasion, a high rate of eventual metastasis and overall poor long-term survival [13, 17-21]. In contrast to ACC, PLGA, has a much lower risk of recurrence, a good local control after a wide local excision and rarely metastasizes $[5,6,13,22-24]$. Because of the aggressive behavior of ACC, it is important to distinguish it from other benign and malignant neoplasms of the head and neck, including those that can mimic ACC in small biopsies [25].

C-kit (CDI17); is a proto-oncogene located on the long arm of chromosome $4[26,27]$. C-kit is also known as kit, stem cell factor receptor, mast cell growth factor receptor, steel factor receptor, and pl45. It encodes a transmembrane receptor-type protein tyrosine kinase that is structurally related to the platelet-derived growth factor receptor and the colony stimulatory factor receptor [28]. In addition to hematopoiesis, c-kit has been shown to play a role in normal migration and development of germ cells and melanocytes. Moreover, it plays an important role in cell proliferation, differentiation, apoptosis and adhesion [29]. In human neoplasia, the c-kit tyrosine kinase receptor pathway has been implicated in tumor development and progression. The c-kit is thought to promote cell transformation and tumorigenicity via auto-/paracrine stimulation in a variety of human tumors, either with or without activating c-kit mutations [30]. In a number of various tumors, c-kit expression has recently been implicated as an adverse prognostic indicator, including adenocarcinoma and squamous cell carcinoma of the lung [31] and endometrial adenocarcinoma [32]. In neuroblastoma, c-kit expression has been associated with lower stage at presentation and found to be an independent predictor of event free survival [33]. In advanced serous carcinoma of the ovary, c-kit expression has been associated with chemotherapy resistance [34].

Galectins are a growing family of proteins defined by their affinity for $\beta$-galactosides and by conserved sequence elements [35]. Galectin-3 is one of the most extensively investigated members of this family concerning with cancer. Galectin-3 was shown to be involved in various biological events, including cell growth, adhesion, differentiation, apoptosis [36], angiogenesis [36, 37], tumorigenesis [38], and metastasis [39]. Unlike many galectins, such as galectin- $1,-7$, and -9 , galectin- 3 was reported to be an antiapoptotic molecule [40]. Overexpression of galectin-3 has been shown to correlate with tumor progression and metastasis in renal [41], tongue [42], thyroid [43], and prostatic cancers [44]. In contrast, galectin-3 down-regulation has been reported during the progression of cancers of the breast [45] and uterus [46]. There are several studies investigating the expression of galectin-3 in head and neck squamous cell carcinomas and most of these studies demonstrated the relationship between the galectin-3 expression and the biological behavior in tumors from the various head and neck sites $[42,47,48]$.

PLGA and ACC have several overlapping histological patterns, including cribriform, tubular and solid patterns. Therefore, histopathological distinction of PLGA and ACC in minor salivary glands is a problem especially in small biopsies [15]. Numerous studies have utilized several immunohistochemical markers in attempts to distinguish between PLGA and ACC [15, 49]. This study examines the potential use of c-kit and galectin- 3 as ancillary markers for distinguishing PLGA from ACC.

\section{Material and Methods}

\section{Tissues}

Tissue samples were all archival material. Twenty cases were collected from the Pathology Department in Oncology Center, Mansoura University Mansoura, Egypt. They were diagnosed as PLGA ( 8 cases) and ACC (12 cases). The present study protocol was reviewed and approved by the Institutional Review Board, Faculty of Dentistry, Mansoura University, Mansoura, Egypt. Evaluations were done for all patients after they granted informed consents.

Four-micron thick sections were cut on positive charged slides for hematoxylin and eosin (H \& E) and immunohistochemistry. All $\mathrm{H} \& \mathrm{E}$ stained slides were reviewed and the diagnoses were confirmed.

\section{Immunohistochemistry}

Tissue sections were deparaffinized in xylene, rehydrated in graded alcohols, and washed with phosphate-buffered saline (PBS) ( $\mathrm{pH} 7.4)$. Endogenous peroxidases were then blocked with $3 \%$ hydrogen peroxide for $10 \mathrm{~min}$. Heat-induced antigen retrieval was performed in $10 \mathrm{mM}$ citrate buffer for $2 \mathrm{~min}$ at $100{ }^{\circ} \mathrm{C}$. To reduce nonspecific binding, block solution (ScyTek, Utah, USA) was applied for $5 \mathrm{~min}$. The sections were incubated with either mouse monoclonal antibody to galectin-3 (clone 9C4, dilution 1:80, Thermo Fisher, Fremont, USA) or the primary antibody $(\mathrm{CDl} 17 / \mathrm{c}$-kit/SCF Receptor clone: Ab-6; ready-to-use; rabbit polyclonal antibody, NeoMarkers, Labvision, USA) and the sections were incubated overnight at $4{ }^{\circ} \mathrm{C}$. The final reaction product was developed in diaminobenzidine tetra-hydrochloride $(\mathrm{DAB})$ mixture for 10 minutes. Finally, the slides were counter stained with hematoxylin. 
The staining condition was adjusted using gastro intestinal stromal tumor to express c-kit and breast carcinoma to express galectin-3 as positive controls. Negative controls were obtained by omitting the primary antibodies. Both positive and negative controls were included in all runs.

\section{Digital image analysis}

Slides were photographed using Olympus ${ }^{\circledR}$ digital camera installed on Olympus ${ }^{\circledR}$ microscope with $1 / 2$ X photoadaptor, using $\times 40$ objective. The images were analyzed on Intel ${ }^{\circledR}$ Core $\mathrm{I}^{\circledR}{ }^{\circledR}$-based computer using VideoTest Morphology ${ }^{\circledR}$ software (Russia) with a specific built-in automated object counting routine for immunohistostain analysis and stain density.

\section{Evaluation of c-kit immunostaining}

The evaluation system for c-kit immunostaining proposed by Miliaras et al. [50] was followed. It included evaluation of the intensity as well as the extent of staining. The intensity of staining was graded as either absent, weak, moderate, or strong ( 0 to 3 scale). Tissue mast cells, which stain $3+$, served as a positive control and were used as an internal scoring guide [51]. The extent of staining was categorized as $0 \%$, less than $10 \%$, between $10 \%$ and $50 \%$, between $50 \%$ and $80 \%$, and more than $80 \%$ ( 0 to 4 scales). Aggregate total scores of both intensity and extent of staining were then calculated and recorded for each case (range: $0-7$ ).

\section{Evaluation of galectin-3 immunostaining}

Galectin-3 cytoplasmic expression was considered to be positive. Tumor cell immunoreactivity was scored as fol- lows: $(-)$ : $100 \%$ of cells were negative, mild $(+): 0 \%-$ $>25 \%$, moderate $(++): 25 \%-50 \%$, and intense $(+++)$ : $>50 \%$ of the cells were positive.

\section{Statistical analysis}

Data are expressed as mean value $\pm S D$ and median. For comparisons between two groups, Mann-Whitney test was used while for more than two groups Kruskal-Wallis test was used for comparison followed by Wilcoxon multiple comparison test, using SPSS for Windows (15.0 Version). Kendall's Tau-b Correlation was used to assess relations between variables. Differences were considered statistically significant when $p<0.05$.

\section{Results}

In the present study, all the tumors were intraoral, and the palate was the most common site $(n=10)$. Our study included twenty cases of ACC and PLGA with a ratio of $3: 2$. Twelve patients $(60 \%)$ were women and 8 $(40 \%)$ were men, with an average age of 52 years. The age range was 22 to 75 years. Of these tumors, five (25\%) arose in major salivary glands; fifteen $(75 \%)$ in the minor salivary glands. The most common ACC subtype was the cribriform pattern (50\%). There were three tumors (25\%) with solid pattern. The remaining ACC cases were tubular pattern (25\%) (Table I).

Table I Shows the numbers and percentages of the different histological subtypes of ACC studied cases

$\begin{array}{lcc}\text { ACC variants } & \text { Number } & \text { Percent }(\%) \\ \text { Tubular } & 3 & 25.0 \\ \text { Cribriform } & 6 & 50.0 \\ \text { Solid } & 3 & 25.0 \\ \text { Total } & 12 & 100.0\end{array}$

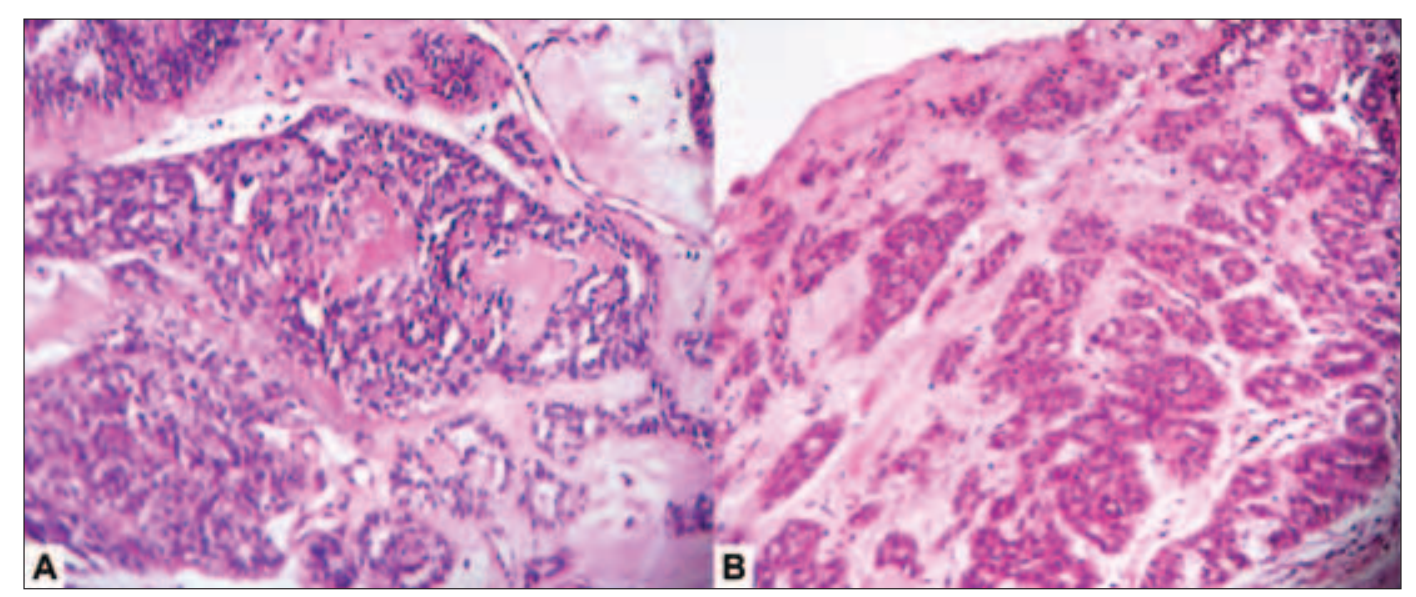

Fig. 1. PLGA exhibited different growth patterns within the same tumor. The cells of these tumors were arranged in solid nests, cribriform, cystic, and tubular patterns $\rightarrow$ pseudo-adenoid cystic appearance. The stroma was mucoid in nature in some cases $(A)$ or slightly eosinophilic hyalinized in other cases $(B)$. $(\mathrm{H} \& \mathrm{E} \times 100)$ 


\section{El-Nagdy et al.}

\section{Microscopical results}

Histologically, PLGAs were characterized by the presence of monotonous cells with a wide spectrum of growth patterns within the same tumor. These tumor cells were arranged in solid nests, trabeculae, cribriform, papillary, cystic, and tubular patterns. Two of these tumors showed perineural invasion. All these microscopical features provided pseudo-adenoid cystic appearance. This tumor cells were round to polygonal in shape, of small to medium size, with indistinct cellular borders and with abundant pale eosinophilic cytoplasm. The nuclei were round to ovoid or spindled and containing vesicular nuclear chromatin in most of cases. The nuclei were more basophilic in some areas. The stroma was mucoid in nature in some cases and slightly eosinophilic hyalinized in other cases (Fig. 1).

ACC exhibited the growth patterns identified in PLGA. In contrast with PLGA, the cells of ACC were small and cuboidal exhibiting deeply basophilic nuclei and little cytoplasm (Fig. 2).

\section{Immunobistopathological results}

Cytoplasmic immunoreactivity for c-kit was detected in all studied cases of ACC (100\%) (5+: 3 cases; 4+: 6 cases; $3+: 3$ cases) and in 25\% of PLGA (2+: 2 cases). A distinct pattern of c-kit immunoreactivity was noted among the tubular and cribriform subtypes of ACC cases where the inner epithelial cells, but not the outer myoepithelial cells, showed strong staining. This pattern was particularly pronounced in the tubular subtype. In contrast, in the solid subtype of ACC, tumor cells exhibited immunohistochemical evidence of c-kit expression in a diffuse pattern (Fig. 3A). Staining intensity of c-kit was diffuse and weak in the cribriform variant ( 6 tumors; $50 \%$ ), diffuse and strong in solid form ( 3 tumors; $25 \%$ ) and focal and weak in tubular type ( 3 tumors; $25 \%$ ). Meanwhile, in PLGA c-kit immunoreactivity was weak (Fig. 3B).

Galectin-3 was expressed in cytoplasm of all studied ACC (Fig. 4A) and PLGA (Fig. 4B) cases. The lesional cells of both tumors exhibited diffuse and strong galectin-3 immunostaining.

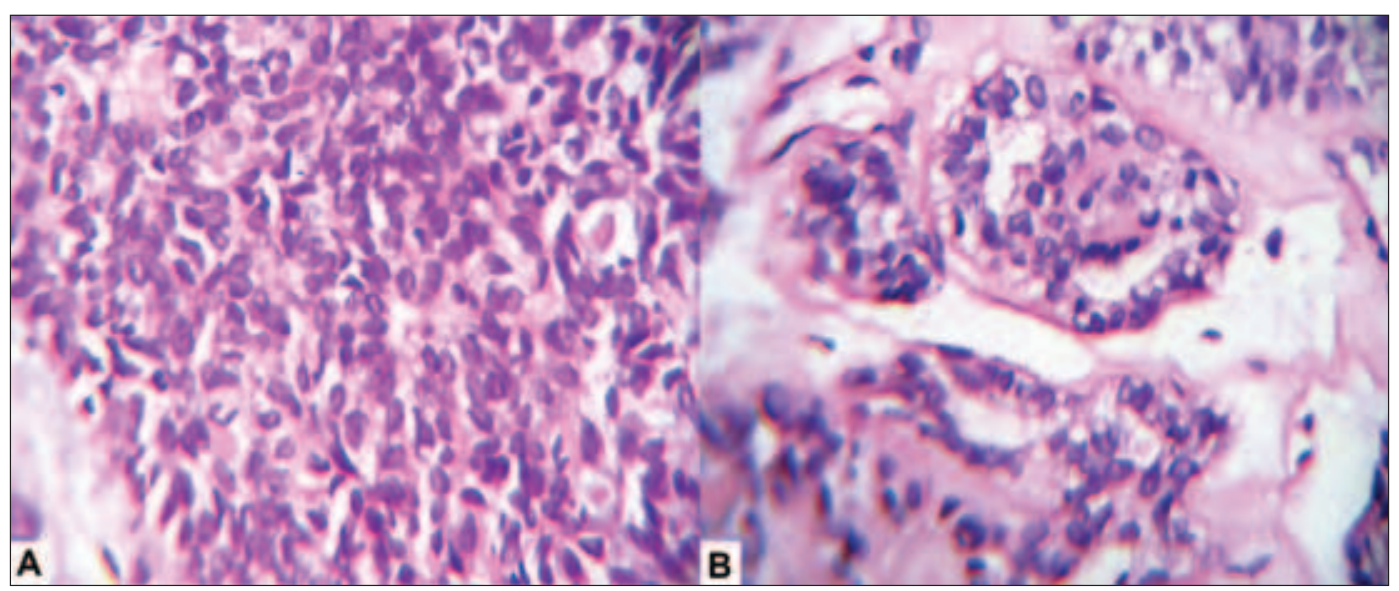

Fig. 2. (A) Solid ACC: this pattern exhibited large sheets of tumor cells with very little or no cystic or ductal spaces. (B) Tubular ACC: the tumor exhibited multiple small duct-like structures or tubules within a hyalinized stroma. The tubular lumina can be lined by one to several layers of cells. $(\mathrm{H} \& \mathrm{E} \times 250)$

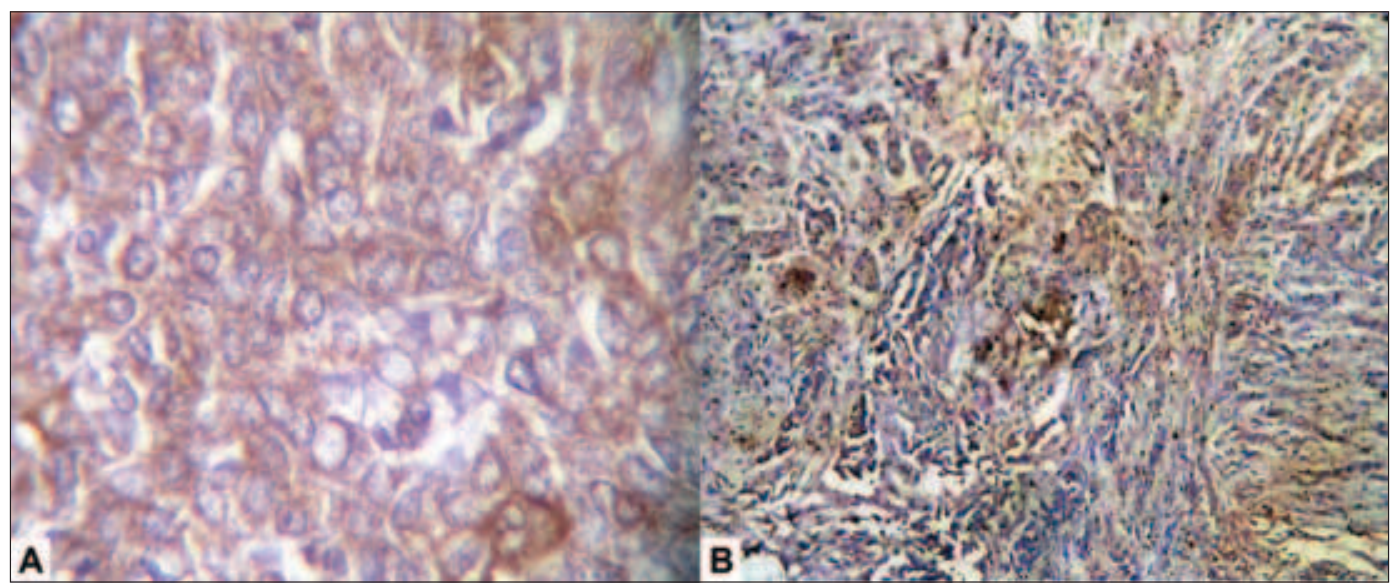

Fig. 3. (A) Solid variant of ACC shows strong and diffuse c-kit immunoreactivity ( ${ }^{*} \mathrm{ABC} \times 250$ ). (B) Weak c-kit immunostaining in PLGA $(\mathrm{ABC} \times 100) .{ }^{*} \mathrm{ABC}=$ avidin-biotin complex 


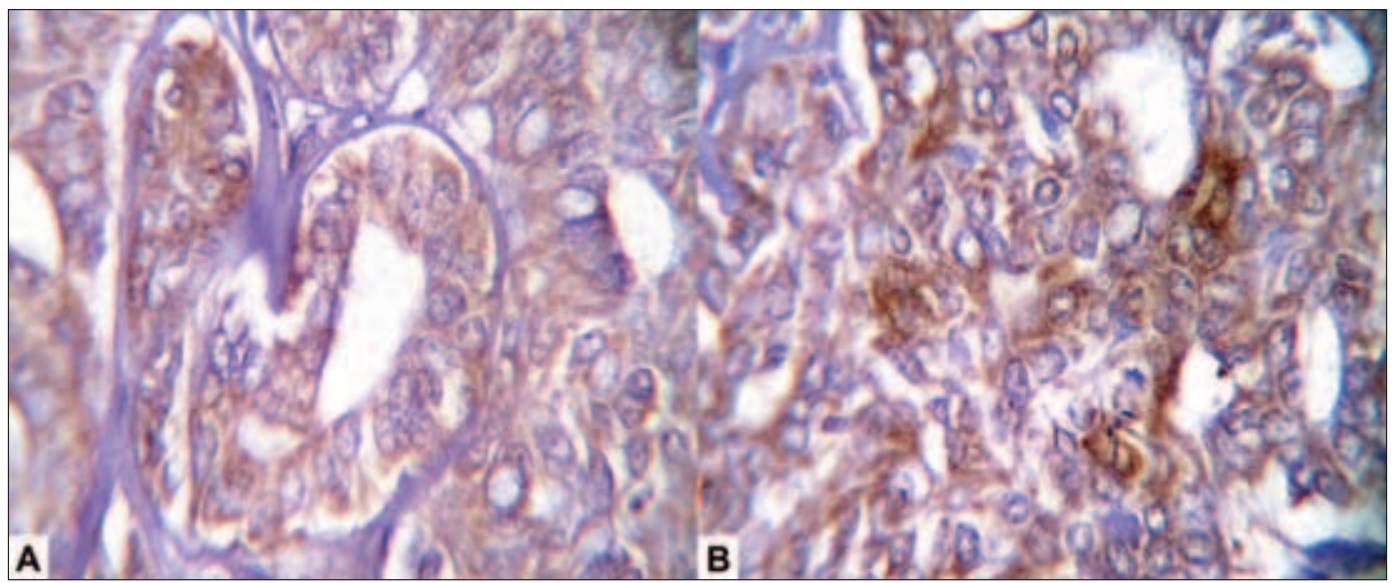

Fig. 4. Diffuse and strong expression of galactin- 3 in tubular variants of ACC $(A)$ and in PLGA $(B) .(A B C \times 250)$

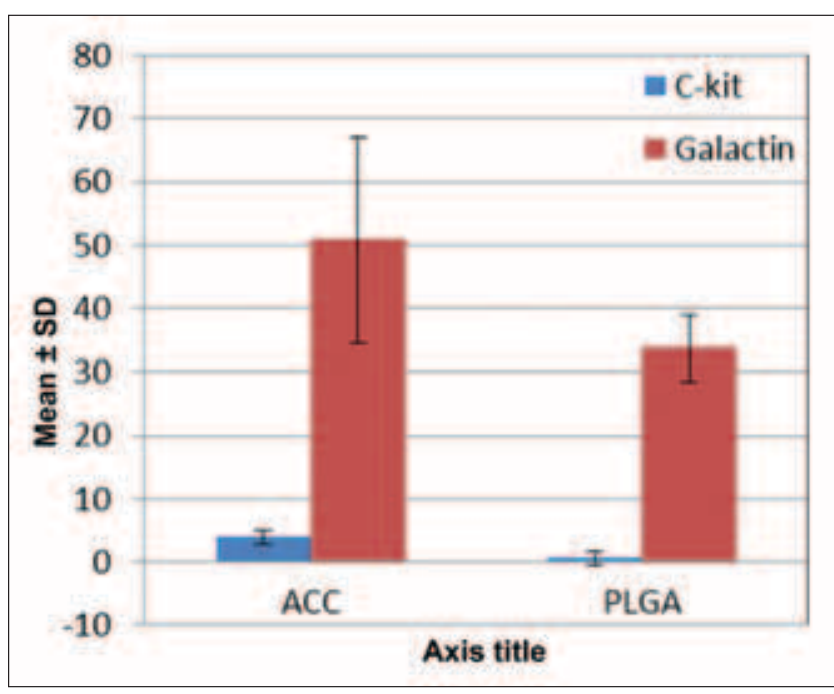

Fig. 5. Histogram shows the mean $\pm S D$ of c-kit and galactin-3 immunoreactivity in ACC and PLGA

The mean \pm standard deviation $(S D)$ as well as the median of expression of $\mathrm{c}$-kit and galectin-3 were higher in ACC cases than PLGA cases (Fig. 5). In this study, there was a significant difference between ACC and PLGA regarding c-kit $(p=0.001)$ and galectin-3 $(p=$ 0.006 ) expressions (Table II).

The median of c-kit and galectin-3 expressions were lower in tubular ACC compared with cribriform type while the highest median was detected in solid ACC variant (Table III). Comparative tests (Kruskal-Wallis test for comparison and Wilcoxon multiple comparison test) revealed a statistically significant difference between ACC variants in relation to expression of $\mathrm{c}-$ kit and galectin-3. Among the subtypes of ACC, the solid variant had the highest staining score for c-kit and galectin-3. This showed that high grade tumors had a statistically significant higher total score of $\mathrm{c}$-kit expression $(p=0.012)$ and galectin-3 $(p=0.014)$. There was no significant difference between tubular and cribriform ACC subtypes in relation to c-kit and galectin-3 expressions (Table III).

By Kendall's $\tau_{\mathrm{b}}$ correlation test, there was a statistically positive correlation between the immunohistochemical staining of c-kit and galectin- 3 in the studied cases of ACC and PLGA (Fig. 6). In relation to the subtypes of ACC, there was a significant correlation between the expression of c-kit and the different histological patterns. Similarly, the same correlation existed between the expression of galectin- 3 and the different histological variants of ACC (Table IV).

\section{Discussion}

It remains difficult to distinguish ACC from PLGA. Although these neoplasms exhibit nearly similar histologic patterns, their biologic behavior is significantly differ-

Table II Shows the mean $\pm S D$ with the median of the immunohistochemical expression of c-kit and galactin-3 in ACC and PLGA cases. Mann-Whitney test was used for comparison

\begin{tabular}{llccc}
\multicolumn{2}{c}{ Comparison } & ACC & PLGA & $p$ value \\
C-kit & Mean $\pm S D$ & $3.92 \pm 0.996$ & $0.63 \pm 1.188$ & $0.001^{*}$ \\
& Median & 4.00 & 0.00 & \\
\hline Galactin-3 & Mean $\pm S D$ & $50.83 \pm 16.214$ & $33.75 \pm 5.175$ & $0.006^{*}$ \\
& Median & 47.50 & 35.00 &
\end{tabular}

* Significant at $p<0.05$ 
El-Nagdy et al.

Table III Shows the median of the immunohistochemical expression of c-kit and galactin-3 for ACC subtypes. Kruskal-Wallis test was used for comparison followed by Wilcoxon multiple comparison test

$\begin{array}{lcccrr}\text { Comparison } & \text { ACC } & \text { Tubular } & \text { Cribriform } & \text { Solid } & p \text { value } \\ \text { C-kit } & \text { Median } & 3 & 4 & 5^{\text {ab }} & 0.012 \\ \text { Galactin-3 } & & 35 & 47 & 75^{\text {ab }} & 0.014\end{array}$

Significant at $p<0.05$

a Significance between tubular and cribriform or tubular and solid groups for c-kit and galactin-3

${ }^{\mathrm{b}}$ Significance between cribriform and solid groups for c-kit and galactin-3

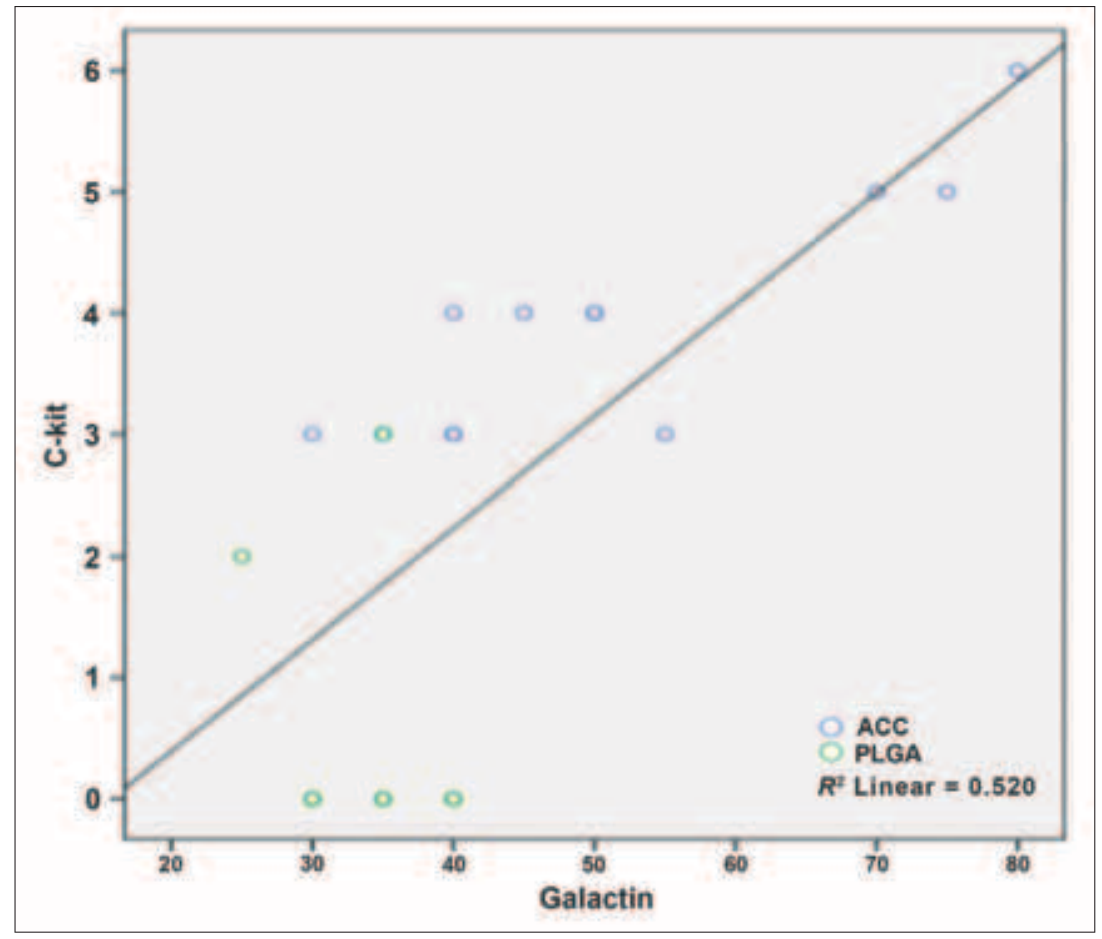

Fig. 6. Shows the positive correlation between c-kit and galectin-3 in ACC and PLGA

Table IV | Kendall's $\tau_{\mathrm{b}}$ correlations

$\begin{array}{lcc}\text { Comparison } & r & p \\ \text { C-kit \& galactin-3 } & 0.63 & 0.000 \\ \text { C-kit \& types of ACC } & 0.83 & 0.002 \\ \text { Galactin-3 \& types of ACC } & 0.81 & 0.001\end{array}$

Significance when $p<0.05$

ent $[11,13]$. The present study demonstrated c-kit immunoreactivity in all studied ACCs. This finding is in agreement with Jeng et al. [25] and Holst et al. [52] who mentioned that ACCs of major and minor salivary glands have been reported to express c-kit protein. Other studies indicate that c-kit is expressed in most ACC cases $(34 / 36)$, raising the possibility that c-kit might be useful as an ancillary marker for this tumor [20]. Moreover, Arber et al. [53] and Albers et al. [54] found that c-kit expression was present in $80 \%$ to $100 \%$ of ACC. In accordance, Edwards et al. [55] mentioned that c-kit immunoreactivity was uniformly positive in the cytoplasm of neoplastic cells in ACCs $(15 / 15,100 \%)$.

Like previous reports, the pattern and intensity of c-kit immunostaining in ACC in this study varied with the different histological subtypes, with the finding that more aggressive tumors showed greater staining intensity $[24,56]$. The solid type showed diffuse reactivity compared to luminal expression in the cribriform and tubular variants. C-kit expression primarily in the inner cell layer with no expression in the outer myoepithelial cells within the tubular and cribriform variants indicates that the myoepithelial cells do not express c-kit [24]. The variable patterns and intensity of staining observed in ACC may be the result of a loss of cellular heterogeneity in the solid variant, with the differentiation primarily along the line of the luminal cell layer, and may correlate with the worse clinical course of the solid variant of 
ACC [57]. Meanwhile, the cribriform pattern exhibited higher $\mathrm{c}$-kit reactivity than the tubular pattern alone, others found c-kit expression to be higher among solid and tubular subtypes than the cribriform subtype [20]. In contrast, Freier et al. [57] showed staining intensity of the solid type to be significantly lower than the cribriform and tubular subtypes, an unexpected finding since solid ACC is clinically more aggressive and may inherit a higher number of cytogenetic aberrations. Moreover, the studies conducted by Seethala et al. [58] and Meer et al. [59] suggested that c-kit staining is more frequently found in well-differentiated ACC tumors and is possibly lost during dedifferentiation.

In the current work, indistinct and low expression of c-kit in PLGAs was found. This has been confirmed in other studies. Schwarz et al. [60] showed that c-kit expression was virtually lacking in PLGAs. In addition, Penner et al. [24] suggested that in histologically ambiguous salivary gland tumors, or in the setting of a limited biopsy, the absence or weak immunoexpression of c-kit may serve as additional evidence for the diagnosis of PLGAs. On the other hand, Edwards et al. [55] identified positive c-kit immunoreactivity in the majority of PLGAs $(16 / 17,94 \%)$, with at least $25 \%$ of the tumor cells being positive

An interesting observation noted in the present study was that ACC showed a significantly higher immunohistochemical expression of c-kit compared with PLGA $(p \leq$ $0.001)$. These results are supported by previous results. Beltran et al. [49] demonstrated a statistically significant difference in c-kit expression between the tumors, with $100 \%$ c-kit immunoreactivity in ACC and no expression in $80 \%$ of PLGA. Others reported greater positive cytoplasmic c-kit expression in ACCs ( $>50 \%$ in $80-83 \%$ of cases), with no or minimal staining in PLGA $(<50 \%$ in $41 \%$ of cases) $[56,61]$. Moreover, PLGA showed a significantly weaker expression of c-kit when compared to ACC showing better prognosis than ACC [49].

These differences may be due to the use of different antibodies and the lack of standardized c-kit immunostaining and a scoring protocol. The differences may also be partly associated with the distribution of solid and cribriform variants in different series, because solid ACC have shown more diffuse and intense staining, whereas cribriform ACC showed staining in the luminally differentiated cells only $[55,62]$. The discrepancies in the specificity of c-kit staining are reported to be due to the variability of the primary antibodies selected and the influence of factors such as differences in immunohistochemical protocols (including deparaffination, epitope retrieval methods, dilutions, detection reagents used, and immunohistochemical methods), the varying methods of evaluating immunoreactivity, and the limited number of cases reviewed $[49,56,61]$.

Recent researches showed that galectin- 3 can be a useful and reliable marker for predicting the aggres- siveness of different tumors due to its involvement in cell growth, adhesion, differentiation, angiogenesis, apoptosis, tumorigenesis, and metastasis $[48,63,64]$. Honjo et al. [42] observed that enhanced expression of galectin-3 in the cytoplasm was associated with a reduced level of disease-free survival in patients with tongue cancers. Piantelli et al. [65] found a significant correlation between galectin-3 tumor positivity and longer relapse-free periods and overall survival in patients with node-negative laryngeal squamous cell carcinomas.

This study revealed that galectin-3 was expressed in all studied cases of ACC and PLGA. ACC showed a significantly higher immunohistochemical expression of galectin-3 compared with PLGA $(p \leq 0.006)$. The distinction between ACC and PLGA is crucial as ACC has more aggressive course. This coincides with other previous reports, Sunil et al. [11] indicated that the high immunostaining of galectin-3 in ACC may be responsible for their aggressive nature; while PLGA expressed galectin-3 with a significantly lower level compared with ACC and this may be responsible for their indolent nature. In contrast, Xu et al. [66] have showed that galectin-3 was expressed in low-grade salivary gland tumors and reduced in higher grade salivary gland malignancies. In accordance with previous studies, solid ACC expressed galectin-3 with higher levels than other ACC patterns. This could be interpreted by Sunil et al. [11] who suggested that galectin-3 has a potential role in aggressive behavior of solid ACC.

The findings of this study demonstrated a statistically significant positive correlation between the immunohistochemical reactivity for c-kit and galectin- 3 in the studied cases of ACC and PLGA as well as between these expressions in ACC subtypes, further studies with increased number of cases will be recommended to clarify this observation.

\section{Conclusion}

From this study we can conclude that our finding of increased c-kit and galectin-3 expressions in solid than in tubular and cribriform variants of ACC supports the concept of solid variant ACC as a high-grade tumor, this suggests that the overexpression of these markers may be an excellent indicator of biologically more advanced tumors. Moreover, the statistical results support the potential use of c-kit, but not galectin-3, as a meaningful tool to distinguish PLGA from ACC in cases where the diagnosis can be challenging. In addition, the strong uniform expression of c-kit in ACC may suggest a potential role for c-kit inhibitors in the management of ACC. Further researches will be recommended to clarify this suggestion. 


\section{References}

1. Neville BW, Damm DD, Allen CM, Bouquot JE (2009): Oral and maxillofacial pathology, 2nd ed. Saunders, Philadelphia, PA

2. Rapidis AD, Givalos N, Gakiopoulou H, Faratzis G, Stavrianos SD, Vilos GA, Douzinas EE, Patsouris E: Adenoid cystic carcinoma of the head and neck. Clinicopathological analysis of 23 patients and review of the literature. Oral Oncol 41, 328-335 (2005)

3. Fordice J, Kershaw C, El-Naggar A, Goepfert H: Adenoid cystic carcinoma of the head and neck: Predictors of morbidity and mortality. Arch Otolaryngol Head Neck Surg 125, 149-152 (1999)

4. Khan AJ, DiGiovanna MP, Ross DA, Sasaki CT, Carter D, Son YH, Haffty BG: Adenoid cystic carcinoma: A retrospective clinical review. Int J Cancer 96, 149-158 (2001)

5. Buchner A, Merrell PW, Carpenter WM: Relative frequency of intra-oral minor salivary gland tumors: A study of 380 cases from northern California and comparison to reports from other parts of the world. J Oral Pathol Med 36, 207-214 (2007)

6. Paleri V, Robinson M, Bradley P: Polymorphous low grade adenocarcinoma of the head and neck. Curr Opin Otolaryngol Head Neck Surg 16, 163-169 (2008)

7. Jaso J, Malhotra R: Adenoid cystic carcinoma. Arch Pathol Lab Med 135, 511-515 (2011)

8. Nagao T, Gaffey TA, Kay PA, Minato H, Serizawa H, Lewis JE: Polymorphous low-grade adenocarcinoma of the major salivary glands: Report of three cases in an unusual location. Histopathology 44, 164-171 (2004)

9. Batsaki JG, Pinkston GR, Luna MA, Byers RM, Scruba JJ, Tilley GW: Adenocarcinomas of the oral cavity: A clinicopathological study of terminal duct carcinomas. J Laryngol Otol 97, 825-835 (1983)

10. Pelkey TJ, Mills SE: Histologic transformation of polymorphous low-grade adenocarcinoma of salivary gland. Am J Clin Pathol 111, 785-791 (1999)

11. Sunil S, Sreenivasan BS, Jisha T, Soma S, Jubin T, Antony G, Gopakumar D: Polymorphous low grade adenocarcinoma - Case report and review of literature. Oral \& Maxillofac Pathol J l(2), (2010)

12. Young S, Leon M, Talerman A, Teresi M, Emmandi L: Polymorphous low-grade adenocarcinoma of the vulva and vagina: A tumor resembling adenoid cystic carcinoma. Int J Surg Pathol 11, 43-49 (2003)

13. Ellis GL, Auclair PL (1995): Tumors of the salivary glands. In: Atlas of tumor pathology, ed Rosai J, Armed Forces Institute of Pathology, Washington, D.C., pp. 203-228

14. Evans HL, Batsakis JG: Polymorphous low grade adenocarcinoma of minor salivary glands: A study of 14 cases of a distinctive neoplasm. Cancer 53, 935-942 (1984)

15. Darling MR, Schneider JW, Phillips VM: Polymorphous lowgrade adenocarcinoma and adenoid cystic carcinoma: A review and comparison of immunohistochemical markers. Oral Oncol $38,641-645$ (2002)

16. Barnes L, Eveson JW, Reichart P, Sidransky D (2005): World Health Organization classification of tumors: Pathology and genetics of head and neck tumors. IARC Press, Lyon

17. Vrielinck LJ, Ostyn F, van Damme B, van den Bogaert W, Fossion $\mathrm{E}$ : The significance of perineural spread in adenoid cystic carcinoma of the major and minor salivary glands. Int J Oral Maxillofac Surg 17, 190-193 (1988)

18. Tomich C (1991): Adenoid cystic carcinoma. In: Surgical pathology of the salivary glands, ed Ellis G, WB Saunders, Philadelphia, PA, pp. 333-349

19. Ellis GL, Auclair PL (1996): Tumors of the salivary glands. Armed Forces Institute of Pathology, Washington, D.C.

20. Mino M, Pilch BZ, Faquin WC: Expression of KIT (CD117) in neoplasms of the head and neck: An ancillary marker for adenoid cystic carcinoma. Mod Pathol 16, 1224-1231 (2003)
21. Kokemueller H, Eckardt A, Brachvogel P, Hausamen JE: Adenoid cystic carcinoma of the head and neck - A 20 years' experience. Int J Oral Maxillofac Surg 33, 25-31 (2004)

22. Castle JT, Thompson LD, Frommelt RA, Wenig BM, Kessler HP: Polymorphous low grade adenocarcinoma: A clinicopathologic study of 164 cases. Cancer 15, 207-219 (1999)

23. Evans HL, Luna MA: Polymorphous low-grade adenocarcinoma: A study of 40 cases with long-term follow up and an evaluation of the importance of papillary areas. Am J Surg Pathol 24, 1319$1328(2000)$

24. Penner CR, Folpe AL, Budnick SD: C-kit expression distinguishes salivary gland adenoid cystic carcinoma from polymorphous low grade adenocarcinoma. Mod Pathol 15, 687-691 (2002)

25. Jeng YM, Lin CY, Hsu HC: Expression of the c-kit protein is associated with certain subtypes of salivary gland carcinoma. Cancer Lett 154, 107-111 (2000)

26. Yarden Y, Kuang WJ, Yang-Feng T, Coussens L, Munemitsu S, Dull TJ, Chen E, Schlessinger J, Francke U, Ullrich A: Human proto-oncogene c-kit: A new cell surface receptor tyrosine kinase for an unidentified ligand. EMBO J 6, 3341-3351 (1987)

27. d'Auriol L, Mattei MG, Andre C, Galibert F: Localization of the human c-kit protooncogene on the q11-q12 region of chromosome 4. Hum Genet 78, 374-376 (1988)

28. Fletcher JA: Role of KIT and platelet-derived growth factor receptors as oncoproteins. Semin Oncol 31, 4-11 (2004)

29. Hussein MR, Haemel AK, Wood GS: Apoptosis and melanoma: Molecular mechanisms. J Pathol 199, 275-288 (2003)

30. Smithey BE, Pappo AS, Hill DA: C-kit expression in pediatric solid tumors: A comparative immunohistochemical study. Am J Surg Pathol 26, 486-492 (2002)

31. Pelosi G, Barisella M, Pasini F, Leon ME, Veronesi G, Spaggiari L, Fraggetta F, Iannucci A, Masullo M, Sonzogni A, Maffini F, Viale G: CD117 immunoreactivity in stage I adenocarcinoma and squamous cell carcinoma of the lung: Relevance to prognosis in a subset of adenocarcinoma patients. Mod Pathol 17, 711-721 (2004)

32. Scobie JV, Acs G, Bandera CA, Blank SV, Wheeler JE, Pasha TL, Salscheider M, Zhang PJ: C-kit immunoreactivity in endometrial adenocarcinomas and its clinicopathologic significance. Int J Gynecol Pathol 22, 149-155 (2003)

33. Krams M, Parwaresch R, Sipos B, Heidorn K, Harms D, Rudolph P: Expression of the c-kit receptor characterizes a subset of neuroblastomas with favorable prognosis. Oncogene 23, 588-595 (2004)

34. Raspollini MR, Amunni G, Villanucci A, Baroni G, Taddei A, Taddei GL: c-KIT expression and correlation with chemotherapy resistance in ovarian carcinoma: An immunocytochemical study. Ann Oncol 15, 594-597 (2004)

35. Barondes SH, Cooper DN, Gitt MA, Leffler H: Galectins structure and function of a large family of animal lectins. J Biol Chem 269, 20807-20810 (1994)

36. Krześlak A, Lipińska A: Galectin-3 as a multifunctional protein. Cell Mol Biol Lett 9, 305-328 (2004)

37. Nangia-Makker P, Honjo Y, Sarvis R, Akahani S, Hogan V, Pienta KJ, Raz A: Galectin-3 induces endothelial cell morphogenesis and angiogenesis. Am J Pathol 156, 899-909 (2000)

38. Honjo Y, Nangia-Makker P, Inohara H, Raz A: Down-regulation of galectin-3 suppresses tumorigenicity of human breast carcinoma cells. Clin Cancer Res 7, 661-668 (2001)

39. Raz A, Zhu DG, Hogan V, Shah N, Raz T, Karkash R, Pazerini G, Carmi P: Evidence for the role of 34-kDa galactoside-binding lectin in transformation and metastasis. Int J Cancer 46, 871-877 (1990)

40. Akahani S, Nangia-Makker P, Inohara H, Kim HR, Raz A: Galectin-3: A novel antiapoptotic molecule with a functional $\mathrm{BH}$ (NWGR) domain of Bcl-2 family. Cancer Res 57, 5272-5276 (1997) 
41. Sakaki M, Fukumori T, Fukawa T, Elsamman E, Shiirevnyamba A, Nakatsuji H, Kanayama HO: Clinical significance of galectin-3 in clear cell renal cell carcinoma. J Med Invest 57, 152-157 (2010)

42. Honjo Y, Inohara H, Akahani S, Yoshii T, Takenaka Y, Yoshida J, Hattori K, Tomiyama Y, Raz A, Kubo T: Expression of cytoplasmic galectin-3 as a prognostic marker in tongue carcinoma. Clin Cancer Res 6, 4635-4640 (2000)

43. Xu XC, el-Naggar AK, Lotan R: Differential expression of galectin- 1 and galectin- 3 in thyroid tumors, potential diagnostic implications. Am J Pathol 147, 815-822 (1995)

44. Wang Y, Nangia-Makker P, Tait L, Balan V, Hogan V, Pienta KJ, Raz A: Regulation of prostate cancer progression by galectin-3. Am J Pathol 174, 1515-1523 (2009)

45. Castronovo V, Van Den Brûle FA, Jackers P, Clausse N, Liu FT, Gillet C, Sobel ME: Decreased expression of galectin-3 is associated with progression of human breast cancer. J Pathol 179, 43-48 (1996)

46. van den Brule FA, Buicu C, Berchuck A, Bast RC, Deprez M, Liu FT, Cooper DN, Pieters C, Sobel ME, Castronovo V: Expression of the $67-\mathrm{kD}$ laminin receptor, galectin-1, and galectin-3 in advanced human uterine adenocarcinoma. Hum Pathol 27, 1185-1191 (1996)

47. Piantelli M, Iacobelli S, Almadori G, Iezzi M, Tinari N, Natoli C, Cadoni G, Lauriola L, Ranelletti FO: Lack of expression of galectin-3 is associated with a poor outcome in node-negative patients with laryngeal squamous-cell carcinoma. J Clin Oncol 20 3850-3856 (2002)

48. Plzák J, Betka J, Smetana K Jr, Chovanec M, Kaltner H, André S, Kodet R, Gabius HJ: Galectin-3 an emerging prognostic indicator in advanced head and neck carcinoma. Eur J Cancer 40 2324-2330 (2004)

49. Beltran D, Faquin WC, Gallagher G, August M: Selective immunohistochemical comparison of polymorphous low-grade adenocarcinoma and adenoid cystic carcinoma. J Oral Maxillofac Surg $64,415-423$ (2006)

50. Miliaras D, Karasavvidou F, Papanikolaou A, Sioutopoulou D: KIT expression in fetal, normal adult, and neoplastic renal tissues. J Clin Pathol 57, 463-466 (2004)

51. Pan CC, Chen PC, Chiang H: Overexpression of KIT (CD117) in chromophobe renal cell carcinoma and renal oncocytoma. Am J Clin Pathol 121, 878-883 (2004)

52. Holst VA, Marshall CE, Moskaluk CA, Frierson HF Jr: KIT protein expression and analysis of c-kit gene mutation in adenoid cystic carcinoma. Mod Pathol 12, 956-960 (1999)

53. Arber DA, Tamayo R, Weiss LM: Paraffin section detection of the c-kit gene product (CD117) in human tissues: Value in the diagnosis of mast cell disorders. Hum Pathol 29, 498-504 (1998)

54. Albers E, Lawrie T, Harrell JH, Yi ES: Tracheobronchial adenoid cystic carcinoma: A clinicopathologic study of 14 cases. Chest 125 , 1160-1165 (2004)
55. Edwards PC, Bhuiya T, Kelsch RD: C-kit expression in the salivary gland neoplasms adenoid cystic carcinoma, polymorphous low-grade adenocarcinoma, and monomorphic adenoma. Oral Surg Oral Med Oral Pathol Oral Radiol Endod 95, 586-593 (2002)

56. Epivatianos A, Poulopoulos A, Dimitrakopoulos I, Andreadis D, Nomikos A, Vlahou S, Papazoglou G, Barbatis C: Application of alpha-smooth muscle actin and c-kit in the differential diagnosis of adenoid cystic carcinoma from polymorphous low-grade adenocarcinoma. Oral Oncol 43, 67-76 (2007)

57. Freier K, Flechtenmacher C, Walch A, Devens F, Mühling J, Lichter P, Joos S, Hofele C: Differential KIT expression in histological subtypes of adenoid cystic carcinoma (ACC) of the salivary gland. Oral Oncol 41, 934-939 (2005)

58. Seethala RR, Hunt JL, Baloch ZW, Livolsi VA, Leon Barnes E: Adenoid cystic carcinoma with high-grade transformation: A report of 11 cases and a review of the literature. Am J Surg Pathol 31, 1683-1694 (2007)

59. Meer S, Singh S, Altini M: C-kit and bcl-2 are not useful markers in differentiating adenoid cystic carcinoma from polymorphous low-grade adenocarcinoma. ISRN Pathology 2011, Article ID 415614 (2011)

60. Schwarz S, Müller M, Ettl T, Stockmann P, Zenk J, Agaimy A: Morphological heterogeneity of oral salivary gland carcinomas: A clinicopathologic study of 41 cases with long term follow-up emphasizing the overlapping spectrum of adenoid cystic carcinoma and polymorphous low-grade adenocarcinoma. Int J Clin Exp Pathol 4, 336-348 (2011)

61. Andreadis D, Epivatianos A, Poulopoulos A, Nomikos A, Papazoglou G, Antoniades D, Barbatis C: Detection of C-KIT (CD117) molecule in benign and malignant salivary gland tumours. Oral Oncol 42, 57-65 (2006)

62. Oprea G, Khalil Z, Mesa H: Value of c-kit (CD117) staining in the differential diagnosis of basaloid tumors of the head and neck. Mod Pathol 15, 222A-223A (2002)

63. Nangia-Makker P, Honjo Y, Sarvis R, Akahani S, Hogan V, Pienta KJ, Raz A: Galectin-3 induces endothelial cell morphogenesis and angiogenesis. Am J Pathol 156, 899-909 (2000)

64. Parkin DM, Bray F, Ferlay J, Pisani P: Global cancer statistics, 2002. CA Cancer J Clin 55, 74-108 (2005)

65. Piantelli M, Iacobelli S, Almadori G, Iezzi M, Tinari N, Natoli C, Cadoni G, Lauriola L, Ranelletti FO: Lack of expression of galectin-3 is associated with a poor outcome in node-negative patients with laryngeal squamous-cell carcinoma. J Clin Oncol 20, 3850-3856 (2002)

66. Xu XC, Sola Gallego JJ, Lotan R, El-Naggar AK: Differential expression of galectin- 1 and galectin- 3 in benign and malignant salivary gland neoplasms. Int J Oncol 17, 271-276 (2000) 